\title{
Cervical thymic cyst in adult: a rare entity
}

\author{
Rohaizam Bin Japar Jaafar ${ }^{1 *}$, Glen Johannes Franciscus Kemps ${ }^{1}$, Ing Bing Tan ${ }^{1}$, \\ Alida Annechien Postma ${ }^{2}$
}

\begin{abstract}
${ }^{1}$ Department of ENT, ${ }^{2}$ Department of Radiology and Nuclear Medicine, School for Mental Health and Neuroscience, Maastricht University Medical Center, Maastricht, Netherlands
\end{abstract}

Received: 01 March 2019

Accepted: 11 April 2019

\section{*Correspondence:}

Dr. Rohaizam Japar Jaafar,

E-mail: konno_81@yahoo.com

Copyright: (c) the author(s), publisher and licensee Medip Academy. This is an open-access article distributed under the terms of the Creative Commons Attribution Non-Commercial License, which permits unrestricted non-commercial use, distribution, and reproduction in any medium, provided the original work is properly cited.

\begin{abstract}
Cervical thymic cysts in adults are rare and seldom diagnosed preoperatively as it may mimic other cystic cervical swellings like a branchial cleft cyst. We present our first encounter with an adult-onset cervical thymic cyst presenting as a lateral neck mass as the sole symptom. Clinical, radiological and cytological evaluations are excellent tools to approach and assess cervical thymic cysts. Histopatholgical examination is the only mean to provide a definitive diagnosis. Adult-onset cervical thymic cyst is a rare entity but should be included in the differential diagnosis for lateral neck swelling. Surgical excision is both diagnostic and therapeutic, once malignancy has been exluded.
\end{abstract}

Keywords: Cervical thymic cyst, Thymopharyngeal duct cyst, Cervical schwannoma

\section{INTRODUCTION}

The thymus epithelium is derived from the ectoderm and endoderm of the third and fourth pharygeal pouches, descends inferiorly along the cervical region to the anterior mediastinum and involutes by increasing age. ${ }^{1,2}$ Cervical thymic cysts are rare and reported scarcely. It accounts less than $1 \%$ of all cervical cystic masses in children, and is even more scarce in adults. ${ }^{3,4}$ It can occur anywhere at any level along the path of its descent, from the mandible to mediastinum. ${ }^{5,6}$ This entity is rarely suspected preoperatively in adults as it may mimic other cervical swellings and the definitive diagnosis is only via histopathological examination. ${ }^{7}$

Here, we report a case of cervical thymic cyst in an adult male who presented with a gradually enlarging right upper neck swelling as the only symptom, and discuss about the presentation, radiological, intraoperative and histopathological findings. Interestingly, the diagnosis was made postoperatively via histopathological examinations.

\section{CASE REPORT}

A 25-year-old gentleman presented to our department with three months history of a gradually increasing painless right neck swelling. There was no dysphagia, odynophagia, hoarseness, shortness of breath, stridor or constitutional symptoms. There was no significant past medical or family history.

The neck examination revealed a non-tender solitary, firm swelling right level III measured approximately 4.0 $\mathrm{cm} \times 5.0 \mathrm{~cm}$. The swelling was mobile and non-pulsatile. A flexible nasopharyngolaryngoscopy examination was unremarkable.

A contrast-enhanced computed tomography demonstrated a cystic soft tissue lesion adjacent to the right carotid sheath measuring $6.0 \mathrm{~cm} \times 6.0 \mathrm{~cm} \times 5.0 \mathrm{~cm}$ (Figure 1). A supplementary ultrasound revealed a multicystic lesion closed to the right internal jugular vein and the right carotid artery with multiple reflections and hyperechogenic sedimentation layers within the cyst. A 
cytological puncture was done and showed cyst formation without evidence of malignancy.

Patient subsequently underwent surgical excision via right trancervical approach. Intraoperatively, the mass was located at level III, deep to the sternocleidomastoid muscle and noted to be in continuity with a fibrous cord superiorly and inferiorly (Figure 2). The carotid sheath and its content was clearly identified and preserved. Excision of the tumour was done successfully with preservation of all the major structures. An impression of schwannoma from the cervical plexus was made as it was correlated with the location of the cervical plexus and the presence of the fibrous band connected to the mass.

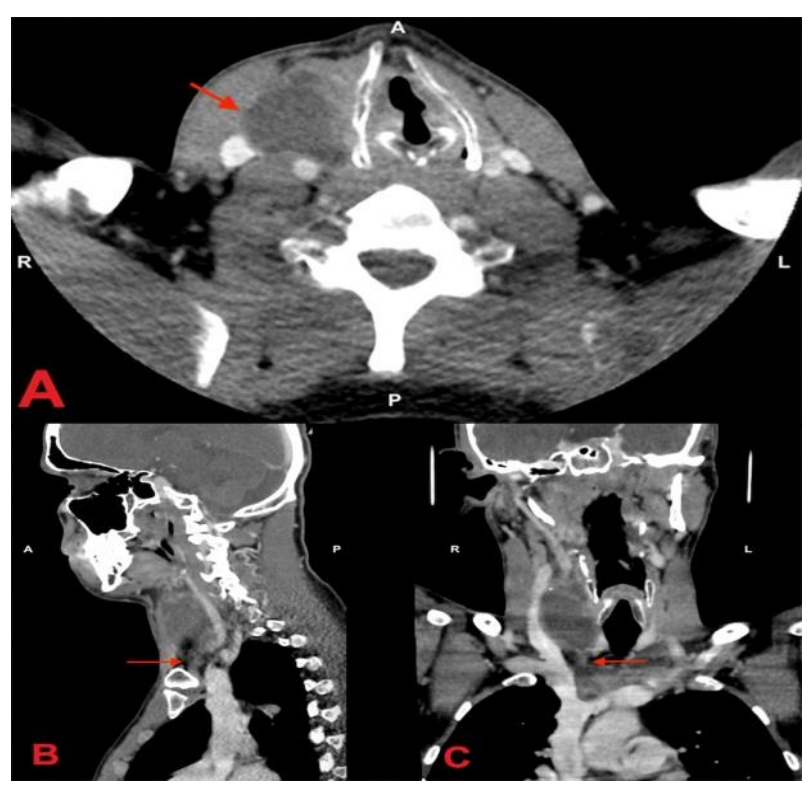

Figure 1: [A] Axial view of a contrast-enhanced computed tomography reveals a huge cystic mass (red arrow) with a mass effect to the adjacent right carotid artery and the right thyroid gland. [B] sagittal and [C]

a coronal view of a contrast-enhanced computed

tomography shows an inferior fibrous cord (red arrow) tracking down to the anterior mediastinum, however the superior cord was not visible $A=$ anterior; $\mathbf{P}=$ posterior; $\mathrm{L}=$ left; $\mathbf{R}=$ right.

The excised specimen was dark red, firm, multilobulated and measured $6.6 \mathrm{~cm} \mathrm{x} 3.3 \mathrm{~cm}$ (Figure 3). Microscopically, it showed a tissue lined with flattened epithelium and chronic lymphocytic inflammatory infiltrates without cellular atypia. There was presence of amorphous eosinophilic material, and Hassall's corpuscle, pathognomonic for a thymic cyst. The histopathological examination confirmed a multilobulated thymic cyst, with one parathyroid gland also present in the specimen.

Postoperatively, patient was well with no evidence of neurological deficits and no evidence of recurrence upon follow-up.

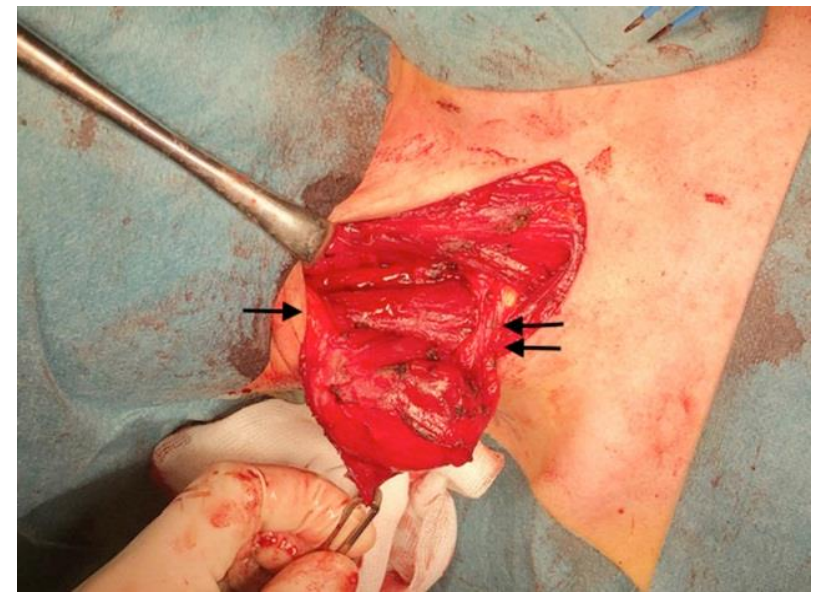

Figure 2: This figure shows the mass was incontinuity with a fibrous-cord structure superiorly [1-arrow] and inferiorly [2-arrows], deep to the

sternocleidomastoid muscle. The carotid sheath and its contains are clearly identified and preserved.

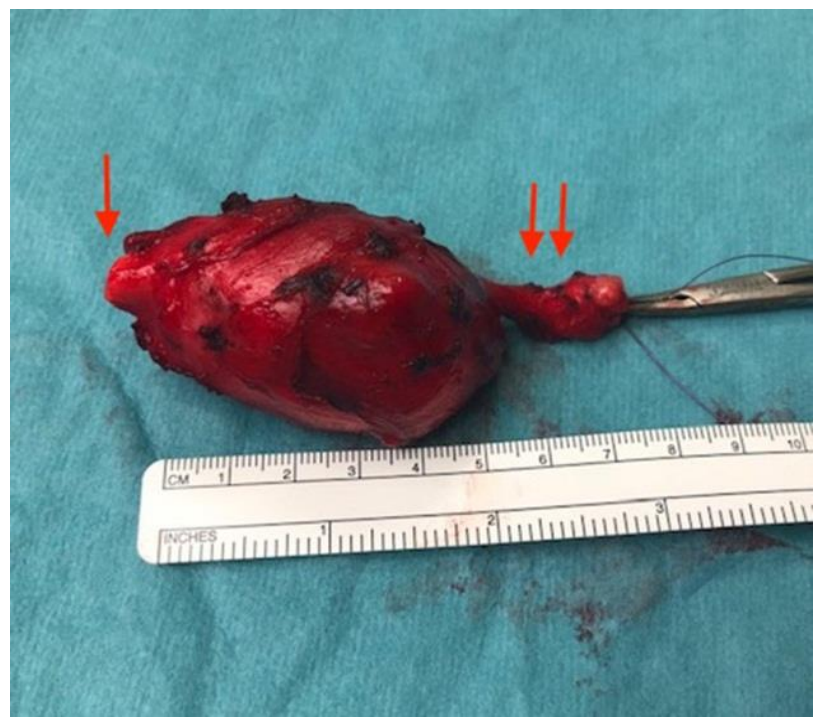

Figure 3: This figure shows a dark red, firm and multilobulated mass, measuring $6.0 \times 3.0 \mathrm{~cm}$ attached to a fibrous-cord structure [1 arrow-superior, 2arrows-inferior]. The excision of the tumour is done successfully with preservation all the major structures.

\section{DISCUSSION}

Cervical thymic cysts are extremely rare in adults and accounts $0.3-1 \%$ of all cervical cysts. It is usually presented in the first decade of life..$^{1-4}$ Most of the thymic cysts are multilobular and asymptomatic as seen in our case. While the incidence is predominantly on the left side, our illustrated case was located on the right side. ${ }^{5}$ The majority of cases are presented with painless and gradually increasing lower lateral neck swelling. However, there are significant reported cases with recurrent neck infection or even compression to the esophagus or airway. ${ }^{1,6,7}$ 
Although cervical thymic cyst is a known entity, it is seldom included in the differential diagnosis of a lateral neck swelling. An extensive systematic review done by Michalopoulous et al in 2011 for adult cervical thymic cyst showed only 36 cases been reported of which all were diagnosed postoperatively except one reported by Berridge et al in 1986. In this particular case, the author only suspected the diagnosis preoperatively without a concrete cytological and radiological evidence. ${ }^{7,8}$

Evaluation through imaging via CT or MRI is an important guidance for this entity but not pathognomonic. Nevertheless, a contrast-enhanced CT scan and MRI provide important information of the soft tissue lesion distinguishing the cyst from lymphangioma or branchial cyst in term of the location and close relation to the mediastinum. A real-time imaging using USG helps to exclude a vascular-origin mass and USG-guided FNAC is performed to obtain tissue. Although an USG-guided FNAC has high diagnostic yield, almost all thymic cyst cases were inconclusive, hypocellular or proteinaceous fluid with non-specific inflammatory cell. 3,9

A pathognomonic histopathological finding shows thymic cyst parenchyma and the Hassal's corpuscles, an eosinophilic epithelial reticular cell in a concentric circle. A cholesterol cleft, histiocytic giant cell and thymic tissue has also been described. ${ }^{5,9}$ Interestingly, there was only one case reported by Delbrouck et al where parathyroid tissue was present in the cyst, which is similar with our case. ${ }^{7,10}$ The author suggested that it is most probably due to the proximity of these two structure and failure to descent to mediastinum or the multipotent ability of thymic cells to differentiate to parathyroid tissues. ${ }^{10}$

Surgical excision is the treatment of choice because the mass is well-encapsulated and has nice surgical plane. However it can be surgically demanding when it is unexpectedly adhered to the carotid sheath. There should be no significant intraoperative or postoperative complications and the recurrence rate is rare.

\section{CONCLUSION}

Cervical thymic cyst is a rare entity in adults but should be included in the differential diagnosis for lateral neck swelling. As previous suggested, the management of this entity, is through surgical excision of the lesion, to reveal the definitive diagnosis once malignancy has been excluded.

\section{ACKNOWLEDGEMENTS}

The authors would like to thank the patient for his permission to write about the case. With much appreciation to all the staff who participated throughout the patient care and/or had an advisory role in writing this case report.

\section{Funding: No funding sources \\ Conflict of interest: None declared \\ Ethical approval: Not required}

\section{REFERENCES}

1. Jaiswal AA, Garg AK, Ravindranath M, Mohanty MK. 'Multiloculated cervical thymic cyst': case report with review of literature. EJENTAS. 2014;15:129-33.

2. Jindal A, Sukheeja D. Unilateral cervical thymic cyst in a child: a rare case report. J Sci Soc. 2016;43:24-6.

3. Sturm JJ, Dedhia K, Chi DH. Diagnosis and management of cervical thymic cysts in children. Cureus. 2017;9(1):e973.

4. Shenoy V, Kamath MP, Hegde MC, Aroor RR, Maller VV. Cervical thymic cyst: a rare differential diagnosis in lateral neck swelling. Case Rep Otolaryngol. 2013;2013:350502.

5. Ji H, Gantwerker E. Cervical thymic cyst. Operative technique in otolaryngology. 2017;28:183-9.

6. Saggese D, Ceroni Compadretti G, Cartaroni C. Cervical ectopic thymus: a case report and review of the literature. Int $\mathrm{J}$ Pediatr Otorhinolaryngol. 2002;66(1):77-80.

7. Michalopoulos N, Papavramidis TS, Karayannopoulou G, Cheva A, Pliakos I, Triantafilopoulou K, et al. Cervical thymic cysts in adults. Thyroid. 2011;21(9):987-92.

8. Berridge DC, Webb AJ. Cervical thymus cyst and thyroglossal cyst carcinoma. Br J Surg. 1986;73:44.

9. Alzahrani HA, Iqbal JM, Abu Shaheen AK, Al Harthi BN. Cervical thymic cyst in an adult. Case Rep Surg. 2014;2014:801745.

10. Delbrouck C, Choufani G, Fernandez Aguilar S, Hassid S. Cervical thymic cyst: a case report. Am J Otolaryngol. 2002;23:256-61.

Cite this article as: Jaafar RBJ, Kemps GJF, Tan IB, Postma AA. Cervical thymic cyst in adult: a rare entity. Int J Otorhinolaryngol Head Neck Surg 2019;5:1088-90. 